\title{
Property Right Type Shops, Centralized Management and Risk Resolution: a Theoretical Framework
}

\author{
Jingfei Ran \\ Zhengzhou University of Science and Technology \\ Zhengzhou, China 450002
}

\begin{abstract}
The property right shop is a commercial real estate of which the ownership is separated from management right. Its emergence solves the problem of rapid recovery of property developers. The property right shop, which is also called property-typed shop, has its economic rationality. From the perspective of potential science, the property right shops have greater information potential than other business modes. The property right shops must be treated with centralized management, so personal ownership must be restricted. There are risks in the investment of property rights shops. We must take measures such as reasonable price comparison, strengthening developers' responsibilities and reducing transaction taxes and fees.
\end{abstract}

Keywords-property right type stores; centralized management; risk solution

\section{INTRODUCTION}

In recent years, with the close integration of Internet commerce and physical retail, some online Internet companies have begun to acquire a large number of physical retail enterprises, such as Alibaba's acquisition of RT-Mart, Jingdong's alignment with Yonghui Supermarket. That means physical retailing has begun a new round of development. Recognizing this business opportunity, some property developers have exploited a large number of Property right type shops, which is also called propertytyped shops, to attract investors for purchase after a few years of after-sales charter. However, property-typed shops face many problems after the expiration of the charter contract, which exposes investors to many risks. How to regulate the sales behavior of property-typed shops to make developers, investors and operators to achieve the balance of their respective interests while preventing and resolving various risks, has become an important issue in the healthy development of the retail industry.

\section{LITERATURE REVIEW}

Property-typed shops refer to a form of real estate product that separates and sells ownership and management rights. It divides the large-scale commercial property that must be used as a whole into small shares. This small-scale property store itself does not have the value of independent use. Property rights become virtual income ownership (Jia Xiuling, 2011). The Property-typed shops divide the shopping mall into a number of shops with small areas for sale. The purchasers of the shops can only profit from the operation instead of operating themselves within a certain period of time, but can't and implement the management mode of separation of ownership and management rights (Fang Xueqin et al., 2005). At present, the research on the property right store is mainly carried out in the following three aspects: First, the legality compliance research of property-based retail sales. Chen Xiaolei (2007) believes that the legal prohibition of property-based shops for "sales charter or leaseback" is unreasonable and after-sales charter or leaseback should not be absolutely prohibited nor be regarded as "illegal". Lin Chenyu et al. (2013) believe that China's current ownership of property-typed shops and related protection system appears scattered and incomplete. There are related regulations in some departmental laws and separate regulations, but not many. The only relevant special laws and regulations is Interim Measures for the management of property right hotels in Haikou implemented by Hainan Province on February 1, 2012. Moreover, the connection between various laws and regulations is not tight enough, and the lack of practicality between them makes the protection of ownership of property-typed shops not effectively implemented. The second is the study of the operation mode of property-typed shops. Adrian (2002) explored the structure and competitive status of the industry from the perspective of the timeshare industry. Chen Jianmei (2014) pointed out that the common sales models of property-typed shops are after-sales leaseback and after-sales repurchase. The sale-leaseback refers to a kind of investment method in which the real estate development enterprise signs the lease agreement with the investor in the name of itself or the business management company, and offsets part of the selling price or pays a certain rental return with the rent during the rent period when sells the commercial house; after-sale repurchase refers to the sale of goods with a condition in which the seller agrees to repurchase the sale of the goods sold in the future. That is to say, in addition to enjoying the return on investment for a period of time, the purchaser can recover the original investment at the expiration of the price exceeding the investment cost. Han Qingrong (2012) believes that after-sales charter is a strategy for developers to attract buyers in the sales process. Developers are now raising prices and then committing to rent return, so the rent for after-sales charters is generally greater than the market rent. The third is the risk research of property-typed shops. Randal (2002) analyzes the rights of consumers in timeshare hotels and the relief issues when 
their rights are infringed, based on consumer interests. Hu Dachun (2011) believes that the leaseback model brings higher risks. As in this game where information is asymmetric, small and medium-sized investors are obviously at a disadvantage. When signing a contract for home purchase, the small owner must sign the entrusted operation agreement and the rental return agreement, while the returning party will certainly not be the developer, usually a shell company that has no connection with the developer. Once the business is badly run, the small owners will suffer huge losses, all of which will have no legal relationship with the developers, and the shell companies that promise to return rents naturally disappear. Pan Yunhua and other scholars (2017) proposed that there will be many problems after the hot sale of virtual property-type shops: various forms of economic disputes, cooperation problems between owners, and the rapid increase in government stability maintenance costs. The cause of this falls to the nominal property rights of retail shops, ineffective legal system of marketing prohibition, and democratic predicament of the owners' autonomy.

In summary, experts and scholars have conducted a series of discussions and research on the legal compliance, business model and risks of property-typed shops. But what is the mechanism of property-based shops? Why do investors insist on this type of investment when facing so many risks? What kind of impact will property-style shops have on the development of new retail in China? This paper intends to analyze and study the mechanism, operation mode and risk prevention of property-typed shops in combination with the relevant theories of economics and potential science.

\section{ANALYSIS OF THE ECONOMIC MECHANISM OF THE PRESENCE OF PROPERTY-TYPED SHOPS}

Property-style shops first appeared in European countries the United States in the 1980s. In the 1990s, it spread to China through Hong Kong, and then quickly spread in large and medium-sized cities in China. The Yansha Square in Beijing, the Caoan International Shopping Mall in Shanghai, and the Taikoo Shopping Mall in Shenzhen were all sold in such method. Then, why is the property-based retail store able to win the approval of investors, and be sold well by the developers successfully?

From the perspective of economics, the reason for the large supply of property-typed shops is, first of all, the increase in demand for large-scale commercial centers in social and economic development. With the arrival of the new retail of "Internet + ", large Internet companies have actively merged with physical retail businesses, so unmanned stores and unmanned supermarkets have emerged. Since entity retail enterprises are close to residents' lives and can satisfy consumers' shopping experience, physical retailing has witnessed a new round of development climax. Second is the development impact of urbanization. With an urbanization rate of $58 \%$, China's still has a long way to go in its ambition to compete developed countries. An important standard of urbanization is whether the number of commercial facilities can meet the consumption needs of residents. Therefore, with the development of China's urbanization, it is also an inevitable trend of the increase in the area of commercial facilities. Large-scale retail commercial facilities, in particular, are a sign of the prosperity of a region and city. Moreover, with the development of some megacities, there has been a multicentered formation, forming a regional commercial center, which also needs a large number of commercial facilities to support. In addition, as megacities are also increasingly suburbanized, and the residents of the central urban areas are moving to the suburbs, these suburbs also need large commercial facilities to support the normal operation of the suburbs.

Second is the need for real estate developers to reduce development costs and increase capital turnover. Real estate developers exploit commercial real estate is to withdraw funds and achieve profitability as soon as possible. However, due to the generally long period of real estate development and large capital occupation, it is the main task of real estate developers to recover funds and realize profit as soon as possible. Selling a large commercial facility with an area of tens of thousands of squares or at least several thousand square feet to one or several investors is obviously an almost impossible task. On the one hand, it's impossible for large retailers to buy. Because light assets are their best choice for large retailers, for the low profit margins of retail companies forces them to accelerate capital turnover and have more cash flow to cope with changing business risks. On the other hand, the investment company may also not buy. Because high returns and high liquidity is what the investment company pursues. But the commercial facilities of several thousand squares or even tens of thousands of square meters will occupy a large amount of cash from the investment company with uncertain return revenue. And there will be a large number of commercial business problems, which far exceeds the operating capacity and business scope of the investment company after the purchase. So the investment company will not buy a lot of commercial real estate alone. So, is it feasible for real estate developers to run business itself? The answer is also no. Because accelerating capital turnover and recovering development costs as soon as possible is the main goal of real estate enterprises, if the commercial facilities developed are all run by themselves, the cash flow of real estate developers will become increasingly less, which will eventually lead the business to be on the verge of bankruptcy. This is also what real estate developers do not want to see.

So, how can large-scale commercial facilities be sold and the investment cost recovered quickly? There is only one way. That is to attract individual investors to buy through minifying commercial facilities. Since the acreage is diminished, the investment area is small, and the investment amount of a single investor is not large, there is less pressure on investors. So real estate developers can achieve rapid return of funds and recover development costs. But why are individual investors willing to invest in this property-typed retail store?

From the perspective of demand, individual investors also have strong need for property-typed shops. The main reasons are as follows: First, individual investors have 
narrow investment channels in China. Stocks, bonds, gold, residential, and independent shops are the main channels for resident investment currently. However, the risk of investing in stocks is relatively high, as most stockholders in China suffer from loss. Investing in bond is low-yielding. The return on gold investment fluctuates. As for house investment, due to the restrictions on purchases in most cities in China, urban households cannot buy more than three houses. Independent shops usually require large capital more than one million Yuan, but this is unbearable for small and medium-sized investors. Therefore, financial products that require small amount and provide stable investment income are in urgent demand for Chinese investors. Second, Chinese people tend to be influenced by the traditional view of "one storefront raise three generations". As many investors believe that a shop is a kind of financial product which brings generous profit to future generations, they deeply believe that owning a store means having a source of wealth. So shops have satisfied consumers' imagination for future wealth appreciation, which give them a lot of psychological gratification. Third, the investment amount of property-typed shops is not large, and the future returns can be expected. Investing in property-typed shops can earn small and medium-sized investors a stable ownership of property at a lower cost. Although this investment income is also risky, it is bearable compared to the high-risk stock, rapid-depreciate bank deposit and the volatile gold price. Investors gain at least a small area of real estate ownership. And the benefit of this ownership for investors is even more valuable than the short-term rental gains obtained from property-typed shops.

In summary, it can be seen that the suppliers of propertytyped shops have introduced the new financial product of property-typed shops under the influence of the favorable factors of the external business environment and the needs of lower costs and higher liquidity within the enterprise while small and medium-sized investors have chosen such financial product based on their own psychological and social investment needs. When the price of the propertytyped shops reaches a level acceptable to both parties, the transaction behavior of the property-typed shops will occur.

As is shown in the following "Fig.1", "a" indicates the price of the property-typed retail store, "b" indicates the supply quantity of the property-typed retail store, "d" indicates the investor's investment curve, and "s" represents the supply curve of the real estate developer. The lower is the price of the property-typed shops, the greater is the investor's investment; the higher is the price of the property-based shops, the greater is the supply of real estate developers. Eventually the two curves become equal at point "E", where the property developer's property-typed retail supply and the investor's investment demand are balanced. Point " $E$ " is the transaction price of the property-typed shop.

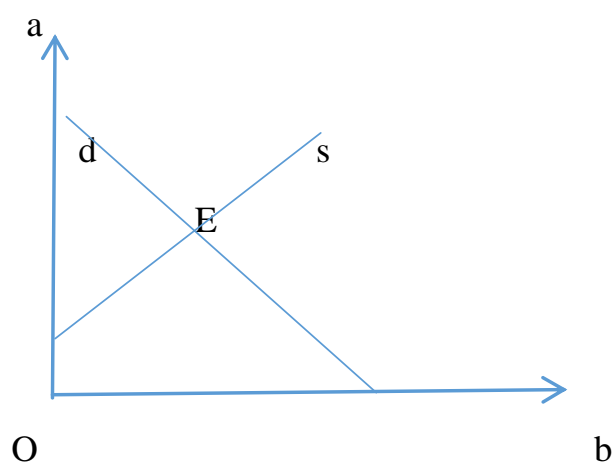

Fig. 1. Transaction price chart of property-style shops.

\section{TheORETICAL ANALYSIS OF THE PRESENCE OF PROPERTY-TYPED SHOPS THROUGH POTENTIAL SCIENCE}

Potential science is a discipline founded by Professor Li Dechang (2005) of Xi'an Jiaotong University on the unification of nature and social sciences. He believes that potential is the root cause of the occurrence and change of things. The potential is information, which is the derivative and slope. The potential is equal to the differences xconnections. Almost all issues of social science and management can be attributed to the differences and connections between things, between people and between people and things (Li Dechang, 2018). That's what "the potential raise everything"(said Laozi) and "everything is proportionate" (thought Pythagoras's) mean.

Why do property-typed shops exist? From the perspective of potential science, property-typed shop can exist because it has a larger information potential than other investment products. The many elements contained in property-typed shops vary widely, but there is a close relationship among them. There remains huge difference between developers of property-typed shops and small and medium-sized investors. Developers focus on the development of commercial facilities. Being more and more experienced, they begin to sell their investment to small investors instead of keep it or sell it to large investors like they did before. Small and medium-sized investors turn to invest in property-typed shops that enable them to invest in smaller amount with lower frequency, which is more professional, after trying stocks, bonds, and bank deposits. Investing in property-based shops, the frequency of investment is frequent, the amount of investment is small and the profession is becoming more and more professional. Inside the community of small and medium-sized investors, due to investors' different personality and experience and funds, the style and requirements of investment will be very different. The operation mode of property-typed shops is quite different from other investment products. Compared with investors investing in other financial products such as independent property shops, stocks, etc. of which the returns are unexpected, the widespread implementation of after-sales charter gives investors a huge psychological difference. The sales method of property-based shops is quite different from other investment products. Property-based shops have segmented large-scale commercial facilities, enabling small 
and medium-sized investors who used to be hopeless to invest in commercial real estate to act as owners of commercial property rights, satisfying their desire of being commercial real estate landlord.

Although there are big differences between the various elements of property-based shops, the links between them are very close. The identity connecting all the elements is the expected return of the property-typed shops to investors. Property-typed shops transactions are able to conclude because property developers and investors are able to agree on a transaction price. This price is the one that can make up for the development cost of the real estate developers and earn profits for them, as well as what small and medium investors are willing to pay for the expected income of the property-typed retail store. Through this price, developers and investors are closely linked. After-sales charter requires close cooperation between developers and small and medium-sized investors. Developers need to fulfill their investment return commitments to small and medium-sized investors. Small and medium-sized investors need to transfer management rights to developers. Therefore, the two parties must be closely linked in order to realize the expected benefits. The segmented property rights of property-typed shops satisfy the desire of small and medium-sized investors as commercial real estate owners, but it also requires investors to abandon their individual requirements and work closely with other investors and commercial real estate owners to achieve centralized operations, in order to maximize the expected benefits.

Therefore, there are huge differences between the various elements of property-typed shops, and there are huge links between the internal elements to obtain the expected income as the shared purpose. Symmetry occurs between Real estate developers and small and medium investors, unified management and expected income, segmented property rights and individual investors. Therefore, a powerful information potential has been formed in property-typed shop investing, attracting small and medium-sized investors to rush to this new mode.

\section{ANALYSIS OF THE CENTRALIZED MANAGEMENT MODE OF PROPERTY-TYPED SHOPS}

Property-typed shops must be run in a centralized manner, which is determined by the characteristics of property-typed shops. Although property rights are scattered in the hands of individual investors, the managing right can only be used through unified and centralized exercise, so that the expected economic benefits can be obtained and the expected benefit can be guaranteed. Within a certain period of the after-sale charter, the centralized exercise of the right to use can be feasible. Because according to the after-sales charter contract, individual investors must give up the right to use for a period of time in order to obtain rental income. But after the expiration of the charter, can individual investors operate independently? The answer is no. Because firstly the personal property rights of the property-typed shops have a virtual nature. The area and location of the personal commercial facilities marked on the developer's drawings are closely connected to other individual investor shops, without space and physical division. Some shops purchased by investors even have become aisles and fire-fighting facilities in reality so property-typed shops are actually a kind of virtual property rights. It is difficult to find the corresponding physical space within large commercial facilities. Secondly, even if the individual investors can find the corresponding physical space and operate alone, it is difficult to achieve. First, the arbitrariness and selectivity of individual decentralized management will cause the large-scale commercial facilities to lose their own characteristics and scientific layout, thus making personal business in an unsustainable state. Second, the individual business operations of individual investors will inevitably damage the interests of the other investments. Single operation violates the original intention of this property rights system, and it will inevitably impair the will and requirements of other investors to concentrate on business. According to the provisions of the Civil Code, when an individual exercises ownership to damage the rights of other neighboring owners, the individual should stop the enforcement of the right.

The centralized operation of property-typed shops is also determined by the characteristics of commercial operations. In order to achieve the desired operational benefits, largescale retail commercial facilities must be rationally arranged according to the business management rules and consumer preferences in a space. According to the theory of scale economy, commercial facilities can only exert the comprehensive benefits of commercial operations on condition that they perform unified management and planning, and arrange the layout of goods in different spaces rationally. According to the principle of commercial agglomeration, gathering products of similar and brand-name in one space will attract consumers. Therefore, seeing from essence of commercial operation, commercial operators must perform unified management in the same space area in order to maximize the economic benefits per unit area, and also to protect the legitimate rights and interests of individual investors in property-typed shops.

At present, there are three main types of centralized business models for property-typed shops:

The first model: real estate developers sell all commercial facilities, and then run by their own business management companies to recruit large retailers. The investor signs two contracts: the purchase contract signed with the real estate developer and the after-sales contract with the commercial company. This model allows developers to quickly recover funds and make up for development costs, but the commercial operating companies that are required to be formed must be familiar with the rules of business operations and have higher requirements for specialization in investment and business operations. For investors, their later profit is more guaranteed because of the cooperation with the developer's own business operation company, so this model is more popular among them.

The second model: Property developers sell all commercial facilities, run them by professional commercial operations companies, and hire large retailers. This model allows real estate developers to transfer unfamiliar business 
operations to professional companies, improving their professionalism. Such companies are familiar with the rules of business operations, their choice of retail business entities and business model is more precise and professional, but the real estate developer must pay a certain management fee to the commercial operation company in the early stage, and the later management expenses are included in the rent of the business operation. For investors, specialized commercial operating companies have laid the foundation for the continued operation of commercial facilities in the later period, and the rent of shops has been relatively reliable. Investors need to pay a certain amount of rent later to pay for management fees later, though.

The third mode: the real estate developer sells part of the commercial facilities, and keeps the rest to be run by the property company. This model can solve a part of the capital demand and make up for part of the development cost for real estate developers. At the same time, when the business is well-operated, they can enjoy part of the rental income. And when the shop becomes a mature shop, the developer sells it to get a part of the premium income. For investors, because developers hold a part of their properties, developers will pay more attention to commercial operations. Investors will enjoy free riders as the developers operate on the property, and the rental income will be more secure in the later period.

\section{THE RISK OF PROPERTY-TYPED SHOPS AND ITS SOLUTION}

Any investment has certain risks. As an investment product, property-based shops must have some risks, mainly including the following four:

\section{A. Price Risk}

When investing in property-based shops, individual investors may face real estate developers raising the price of the store to a level that exceeds the normal market price. It is possible for the developer to reflect the rent that was later returned to the investor in the store price in advance.

\section{B. Credit Risk}

After the individual investor invests in the proper-typed shop, the rent promised by the developer for sale and leaseback cannot be fulfilled. Although the contract for sale and leaseback has been signed in the previous period, the developer or the commercial operation company will not execute the contract in the later stage, so that individual investors cannot get the rent.

\section{Business Risk}

After the property-typed shops are rented by large commercial enterprises, when the commercial enterprises cause losses due to poor management, the commercial operation companies cannot receive the rent, so the rental income of individual investors cannot be guaranteed.

\section{Liquidity Risk}

It's difficult for individual investors to sell off at any time the property-typed shops they have bought, because the poor management of shops and the high transaction fees of commercial real estate make the transaction and realization of property-typed shops difficult.

So, how can we resolve the risks of property-typed shops?

The first is to set a reasonable price. When purchasing individual property-typed shops, individual investors should make a rational comparison with similar shops, determine the reasonable price of the store according to the geographical location, operating environment, and developer's scale, and then select the best item with the right price, location, and guarantee for later income. According to the law of market competition, in a perfectly competitive market, setting a high price will inevitably lose investors. So real estate developers must respond to investors at a market price ultimately.

The second is to strengthen the responsibility of the developer. After selling the property-typed shops, developers should fulfill their obligations in accordance with the contract for sale and lease instead of leaving it alone.

Then individual investors can set up owners' committees, in cooperation with commercial operating companies, and select powerful retailers to guarantee the normal rental income later.

The last is in the policy chain, to reduce transaction taxes and fees, and promote property rights transactions. At present, the transaction tax of commercial real estate is too high, basically more than $30 \%$ of the commercial real estate price, such high transaction taxes and fees seriously affect the liquidity of commercial real estate. Therefore, in order to protect the liquidity of property-typed shops, it is necessary to reduce the transaction taxes and fees of commercial real estate to a reasonable level.

\section{CONCLUSION}

This paper analyzes the reasons for the existence of property-typed shops, points out that property-typed shop must be given centralized and unified management puts forward to the risks of property-based shops and some resolving measures. This can drip model function to the new retail revolution that is currently underway in China and optimize China's physical business operation environment. It can also provide certain reference for investors of propertytyped shops. The shortcoming of this paper is that there are few specific case studies on property-typed shops, and the research on the business model of property-based shops needs to be further deepened.

\section{REFERENCES}

[1] Jia Xiuling. Risk Analysis of Virtual Property-based Retail Stores in China[J]. Productivity Research, 2011(12): 227-228+252.

[2] Fang Xueqin, Sun Zheng. Risks and Countermeasures of Propertybased Retail Sales[J]. China Real Estate, 2005(11): 38-39. 
[3] Zhao Bifei. Analysis of the legality of the property-based retail sales and leaseback business model [J]. China Business \& Trade, 2014 (11): 183-184.

[4] Chen Xiaolei. Legal Issues of "Property-style Shops" under the Model of "Unified Management" [J]. Journal of Heilongjiang Administrative Cadre Institute of Politics and Law, 2007(05): 70-72.

[5] Lin Chenyu, Zhang Shuo, Lu Guannan. Legal Regulation of Property Right-style Stores Ownership Restriction[J]. Legal System and Society, 2013(18): 215-216.

[6] Hu Dachun, Sun Qing, Zhao Hongying. Research on China's commercial real estate sale and leaseback model [J]. Finance \& Economy, 2011 (06): 70-72.

[7] Pan Yunhua, Qian Weidong. Research on the governance of virtual property-based shops_- Taking the dispute handling of virtual property-style shops in CA area of $\mathrm{W}$ city as an example[J]. Journal Of Weinan Normal University,2017,32(07):29- 34.

[8] Zhou Zhou. Research on legal issues of property-typed shops [D]. Chang'An University, 2016.

[9] Chen Jianmei. Reflections on the Standardization of Property-based Business Models[J].China Foreign Investment,2014(01):210-211.

[10] Han Qingrong. Several issues that should be paid attention to when evaluating the value of property-based shops [A]. China Real Estate Appraisal and Agency, No. 5, 2012 (total 96) [C].:, 2012: 3.

[11] Lv Jingwei, Yang Hua, Wen Qixiang. The Innovation Path of Business Models in China's Characteristic Towns under the Background of Common Reform[J]. Shanghai Business, 2017(11): 56-59.

[12] Li Dechang. Information Man Management [M], China Social Sciences Press, 2015.

[13] Yan Jingfei. Adverse Selection, Moral Hazard and the Construction of China's Rural Circulation System [J]. Regional Economic Review, 2018 (01): 48-54. 